Int. J. Dev. Biol. 56: 593-604 (2012)

doi: $10.1387 / \mathrm{ijdb} .123499 \mathrm{sr}$

\title{
Hydra, a versatile model to study the homeostatic and developmental functions of cell death
}

\author{
SILKE REITER ${ }^{1}$, MARCO CRESCENZI ${ }^{2}$, BRIGITTE GALLIOT ${ }^{*, 1}$ and WANDA BUZGARIU ${ }^{*, 1}$ \\ ${ }^{1}$ Department of Genetics and Evolution, Faculty of Science, University of Geneva and \\ ${ }^{2}$ Department of Cell Biology and Neurosciences, National Institute of Health, Rome
}

\begin{abstract}
In the freshwater cnidarian polyp Hydra, cell death takes place in multiple contexts. Indeed apoptosis occurs during oogenesis and spermatogenesis, during starvation, and in early head regenerating tips, promoting local compensatory proliferation at the boundary between heterografts. Apoptosis can also be induced upon exposure to pro-apoptotic agents (colchicine, wortmannin), upon heat-shock in the thermosensitive sf-1 mutant, and upon wounding. In all these contexts, the cells that undergo cell death belong predominantly to the interstitial cell lineage, whereas the epithelial cells, which are rather resistant to pro-apoptotic signals, engulf the apoptotic bodies. Beside this clear difference between the interstitial and the epithelial cell lineages, the different interstitial cell derivatives also show noticeable variations in their respective apoptotic sensitivity, with the precursor cells appearing as the most sensitive to pro-apoptotic signals. The apoptotic machinery has been well conserved across evolution. However, its specific role and regulation in each context are not known yet. Tools that help characterize apoptotic activity in Hydra have recently been developed. Among them, the aposensor Apoliner initially designed in Drosophila reliably measures wortmannin-induced apoptotic activity in a biochemical assay. Also, flow cytometry andTUNEL analyses help identify distinctive features between wortmannin-induced and heat-shock induced apoptosis in the sf-1 strain. Thanks to the live imaging tools already available, Hydra now offers a model system with which the functions of the apoptotic machinery to maintain long-term homeostasis, stem cell renewal, germ cell production, active developmental processes and non-self response can be deciphered.
\end{abstract}

KEY WORDS: apoptosis, aposensor, DNA fragmentation, caspase inhibitors, flow cytometry

\section{Apoptosis occurs in multiple contexts in Hydra}

New advances in the field of cell death continuously contribute to show the deep intricacy of the apoptotic machinery with a variety of cell behaviors and developmental processes (Yi and Yuan, 2009; Fuchs and Steller, 2011; Miura, 2011). Indeed knockout and knockdown based studies performed in well-established model organisms such as nematodes, flies and mice provided us with detailed information about the molecular actors that guide the interactions between cell death and cell survival, cell death and cell proliferation, cell death and cell differentiation. However these model systems despite their fabulous genetic potency provide restricted conditions to study these interactions (Podrabsky and Krumschnabel, 2010). Therefore, given the conservation of the apoptotic machinery since basal metazoans (Srivastava et al., 2010) and the multiple impact of cell death in complex cellular and developmental processes, there is a need to extend our focus beyond these appreciated model systems.

Indeed informations obtained from model organisms that are less established in the field of cell death like zebrafish, sea urchin,

Abbreviations used in this paper: AO, acridine orange; APAF1, apoptotic protease activating factor 1; Bcl-2, B-cell lymphoma protein-2; CARD, caspase recruitment domain; CBP, CREB binding protein; CREB, cAMP response element binding protein; DAPI, 4',6 diamidino-2-phenylindole; DD, death domain; DED, death effector domain; DIAP1, Drosophila inhibitor of apoptosis; DISC, death inducing signaling complex; DR, death receptor; EM, electron microscopy; FADD, Fas-associated death domain; gl, gland cell; H. vulgaris, Hydra vulgaris; HS, heat-shock; HyCaspA, Hydra caspase A; HyDDCasp, Hydra caspase with DD domain; hyDEDCasp, Hydra caspase with DED domain; IAP, inhibitor of apoptosis; i-cells, interstitial cells; MOM, mitochondrial outer membrane; MOMP, mitochondrial outer membrane permeabilization; nb, nematoblast; nc, nematocyte; NF-kB, nuclear factor kappalight-chain-enhancer of activated B cells; NISCH, Nischarin protein; nv, nerve cell; RING, really interesting new gene; RIP, receptor interacting protein; RNAi, RNA interference; RSK, ribosomal S6 kinase; $s f-1$, self-feeder 1. 
Xenopus and Hydra as few examples already provided a depth of information (Podrabsky and Krumschnabel, 2010). Among those, Hydra appears as a recently emerged model organism for the elucidation of programmed cell death in the contexts of homeostasis, development and immunity (Cikala et al., 1999; Bottger and Alexandrova, 2007; Galliot and Chera, 2010; Lasi et al., 2010a). The presence of apoptotic bodies in Hydra was first reported in 1989 by Honegger and Tardent who showed that nurse cells transform into apoptotic bodies (Honegger et al., 1989). However cell death and engulfment of cell debris, two features that evoke apoptosis, were previously found in Hydra exposed to cytotoxic drugs (Campbell, 1976; Terada et al., 1988), in head-regenerating tips (Yaross and Bode, 1978), along the body column of wounded or regenerating animals (Fujisawa and David, 1984), in starved animals (Bosch and David, 1984), and at the boundary between heterospecies grafts (Bosch, 1986).

In fact Hydra offers a model system where the permanent selfrenewal of tissues results from a tightly tuned balance between cell proliferation, cell differentiation and cell death (Galliot and Ghila, 2010). When the animals are regularly fed, the level of cell death is very low and takes place only at the extremities of the animals, tentacles and basal disc, where the "old" differentiated cells are eliminated and replaced by juvenile cells arriving from the proliferating body column (see in this issue (Martinez and Bridge, 2012). Once homeostasis is perturbed either upon exogenous stimulus (food restriction, drugs, injury, heat-shock) or upon differentiation events such as gametogenesis, the extent of cell death changes significantly and apoptotic cells and/or engulfed apoptotic bodies can now be observed not only in restricted areas as described above but along the entire body column. In total, eight distinct contexts of programmed cell death were identified in Hydra up to now (see Fig. 1 and key features of each context in Table 1).

\section{Cell death of the nurse cells during oogenesis}

Ovary formation and oogenesis starts in the body column of female animals with the accumulation underneath the ectoderm of interstitial stem cells that become egg-restricted germ cells and the formation of a discrete egg patch where these cells proliferate and enter meiosis (Littlefield, 1991; Nishimiya-Fujisawa, 2012). Among the several thousands of cells that enter meiosis, a single one gives rise to the oocyte whereas the others differentiate into nurse cells that end to shrink, initiate apoptosis, and are engulfed by the oocyte, which constantly increases in size. Indeed cell death plays an essential role during oogenesis in Hydra and cellular analyses over the past 40 years have discovered a quite unusual apoptotic program.

Thanks to ultrastructural studies the presence of apoptotic features in nurse cells (condensed chromatin, membrane blebbing, spherical shape of dying cells,) was already reported in 1972 (Zihler, 1972) and further recognized as evidences of apoptosis in 1989 (Honegger et al., 1989). Interestingly this apoptotic program of the nurse cells is under the control of the oocyte (Miller et al., 2000) and is necessary for oogenesis as shown by the blockade of early but not late oogenesis upon treatment with caspase inhibitors (Technau et al., 2003). In fact the onset of apoptosis in nurse cells starts after the transfer of their cytoplasmic content to the developing embryo (Alexandrova et al., 2005). Then the apoptotic nurse cells are phagocytosed by the oocyte and cell death is arrested: the cells become TUNEL negative and the analysis of

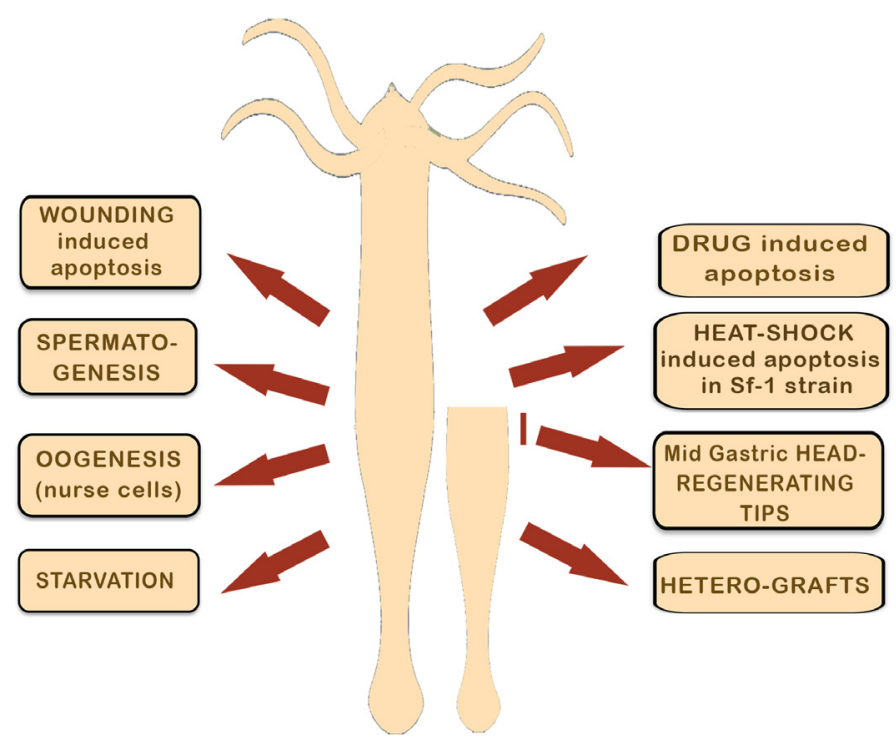

Fig. 1. Cell death occurs in at least eight distinct contexts in Hydra. Apoptosis was identified in multiple distinct contexts in Hydra: 1) upon starvation, when a fraction of cells are committed to death and engulfed by the neighboring epithelial cells; 2) during oogenesis when nurse cells enter cell death when they get engulfed by the oocyte; 3) during spermatogenesis when sperm cell precursors undergo programmed cell death; 4) after wounding as an extended cell death affects differentiating nematocytes; 5) upon exposure to pro-apoptotic drugs as wortmannin and colchicine that rapidly induce a massive apoptosis of interstitial stem cells and their derivatives; 6) upon heat-shock that induces apoptosis of cycling interstitial cells in the sf-1 strain; 7) in the head-regeneration tip after midgastric bisection where the cells from the interstitial cell lineage commit suicide; 8) at the boundary between heterografts. For each context see details and references in Table 1.

DNA fragmentation shows a different pattern, with large, unspecific fragments (Technau et al., 2003; Alexandrova et al., 2005). This arrested apoptosis persist during embryonic development until the hatching phase when the phagocytized nurse cells that show a persistent peroxidase activity, become TUNEL positive and get degraded in the endodermal epithelial cells of the young Hydra (Technau et al., 2003). Hence cell death during oogenesis comprises caspase-dependent and caspase-independent phases. Therefore in Hydra, the role of cell death during oogenesis seems to provide the energy demand for embryo development, similarly to Drosophila and C. elegans.

\section{Cell death during spermatogenesis}

Apoptosis was also evidenced during Hydra spermatogenesis as sperm cell precursors were identified in the phagocytic vacuoles of epithelial cells (Kuznetsov et al., 2001). Here TUNEL staining detected only a few cell types undergoing apoptosis, like the spermatogonial cells and the spermatocytes, whereas AO staining revealed a higher number of positive sperm precursors, in agreement with the large number of positive phagocytic vacuoles identified in epithelial cells. This discrepancy suggested that either AO staining is less specific than TUNEL, or that AO and TUNEL stainings detect distinct phases of apoptosis. In contrast to the evolutionarily conserved role played by apoptosis in oogenesis, the function of apoptosis in spermatogenesis is not well understood yet. Kuznetsov et al., proposed that the epithelial cells actually have an 
active role in spermatogenesis, similar to that played by the Sertoli cells in mammals. Further studies are necessary to elucidate the origin and the nature of the signals that determine the male germ cell precurors to enter apoptosis and thus to confirm the direct involvement of the epithelial cells in the control of spermatogenesis.

\section{Starvation-induced cell death}

In 1984 Bosch and David who were investigating the regulation of the cycling behavior of the epithelial and interstitial cells in starving animals, noted distinct cell behaviors in daily-fed and in starved animals. They noticed in few days starved but not in daily-fed animals the presence of pycnotic nuclei that were phagocytosed by both the ectodermal and the endodermal epithelial (Bosch and David, 1984). They interpreted this "eating behavior" of the epithelial cells as a response of the animals to starvation and proposed that phagocytosis was playing a role in the regulation of cell number in starving Hydra. Indeed it was established since long that Hydra reacts to limited food resources by slowing down its growth, thus decreasing its size but by keeping intact its shape and fitness (Otto and Campbell, 1977). However although counter-intuitive, Bosch and David noticed that the size of the epithelial cells and their proliferating rate was maintained constant over days in starving animals. They thus proposed that the cells produced in excess, epithelial and interstitial cells, are committed to die and thus engulfed by the neighboring epithelial cells as a kind of endogeneously produced nutrient.

Although the original paper was not referring to apoptosis, further re-examination showed that the engulfed cells presented the typical DNA hallmark of apoptosis (Bottger and Alexandrova, 2007). This physiological regulation of cell death extends over the body column as observed in AO staining (Bottger and Alexandrova, 2007) but the dying cells are not precisely characterized. In addition apoptosis affects only a low fraction of cells and thus provides a limited supply. Recently Buzgariu et al., showed that macroautophagy affects a large proportion of the epithelial cells (up to $50 \%$ after 10 days of starvation), likely playing a major role in the survival of animals submitted to weeks of starvation (Buzgariu et al., 2008; Chera et al., 2009a).

\section{Heat-shock induced cell death in the thermosensitive mutant sf-1}

Selective cell death of the interstitial cell lineage can also be induced upon heat shock $\left(26^{\circ} \mathrm{C}-28^{\circ} \mathrm{C}\right.$ instead of $\left.19^{\circ} \mathrm{C}\right)$ in the temperature sensitive $s f-1$ strain of Hydra magnipapillata originally isolated by Sugiyama and Fujisawa (Sugiyama and Fujisawa, 1978) reviewed in (Shimizu, 2012). Indeed a two days heatshock induces apoptosis of all fast cycling cells, i.e. interstitial stem cells and nematoblast progenitors, leaving the contingent of epithelial cells intact (Marcum et al., 1980; Terada et al., 1988). To test which cell types were sensitive to heat-shock, Marcum and colleagues produced chimeric strains, i.e. animals formed by recombining epithelial cells from one strain and the interstitial cells from another strain, - see for review (Shimizu, 2012). The results were very clear, showing that the epithelial cells of the sf- 1 strain are not sensitive to heat-shock (Marcum et al., 1980). However like in the other contexts, the epithelial cells play a major role in the cell death process as they engulf the apoptotic bodies. As a consequence of this massive cell death of the cycling i-cells, the terminally differentiated interstitial cell derivatives, i.e. nerve cells and nematocytes, are no longer replaced and thus progressively

\section{TABLE 1}

\section{VARIOUS CONTEXTS IN WHICH CELL DEATH IS OBSERVED IN HYDRA}

\begin{tabular}{|c|c|c|c|}
\hline Cell death contexts & Methods to detect or regulate cell death & Cell types undergoing cell death & References \\
\hline 1. Oogenesis & AO, Apo-nuc, Casp-inh, DNA-ladder, EM, TUNEL & $\begin{array}{l}\text { nurse cells, } \\
\text { engulfed by the oocyte (arrested apoptosis) }\end{array}$ & $\begin{array}{l}\text { (Zihler, 1972; Honegger et al., 1989; Miller et al., 2000; Technau } \\
\text { et al., 2003; Alexandrova et al., 2005) }\end{array}$ \\
\hline 2. Spermatogenesis & AO, TUNEL & sperm precursor cells & (Kuznetsov et al., 2001) \\
\hline 3. Starvation & AO, Apo-nuc, engulft & not characterized & (Bosch and David, 1984; Bottger and Alexandrova, 2007) \\
\hline 4. Heat-shocked sf-1 & $\begin{array}{l}\text { AO, Apo-nuc, engulft } \\
\text { TUNEL, FACS, }\end{array}$ & i-cells, nb & $\begin{array}{l}\text { (Marcum et al., 1980; Terada et al., 1988; Cikala et al., 1999); } \\
\text { this work }\end{array}$ \\
\hline 5a. Colchicin & AO, Casp-act, Casp-inh, Casp-subst, DNA-ladd, EM, PS & i-cells, nb, nc, nv, gl & $\begin{array}{l}\text { (Campbell, 1976; Terada et al., 1988; Cikala et al., 1999; Cikala } \\
\text { et al., 2004; David et al., 2005) }\end{array}$ \\
\hline 5b. Wortmannin & Apo-nuc, Aposensor, Casp-subst, TUNEL & i-cells, nb, nc, nv, gl & $\begin{array}{l}\text { (David et al., 2005; Bottger and Alexandrova, 2007; Buzgariu et } \\
\text { al., 2008); this work }\end{array}$ \\
\hline 6. Wounding & Apo-nuc, engulft, & differentiating $\mathrm{nb}$ & (Fujisawa and David, 1984) \\
\hline 7. Head regeneration & $\begin{array}{l}\text { Apo-nuc, EM, engulft, PS, TUNEL, Casp-inh, RNAi (CREB, } \\
\text { RSK, CBP), U0126 }\end{array}$ & i-cells, nb, nc, nv, gl & $\begin{array}{l}\text { (Chera et al., 2009b; Galliot and Chera, 2010; Chera et al., } \\
\text { 2011) }\end{array}$ \\
\hline 8. Heterografts & AO, engulft, TUNEL & nc, species susceptibility $(\mathrm{Hv}>\mathrm{Ho})$ & (Bibb and Campbell, 1973; Bosch, 1986; Kuznetsov et al., 2002) \\
\hline
\end{tabular}

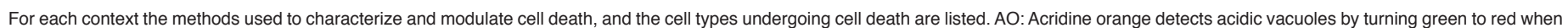

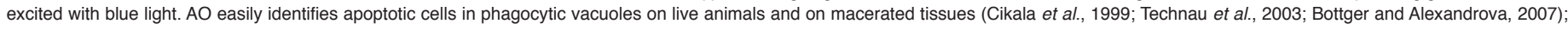

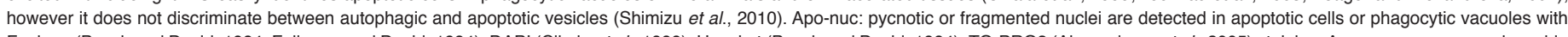

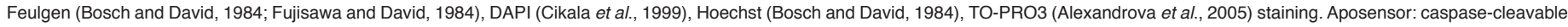

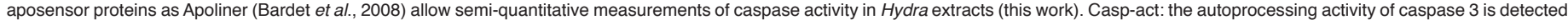

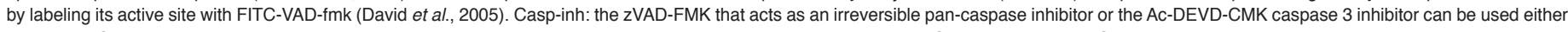

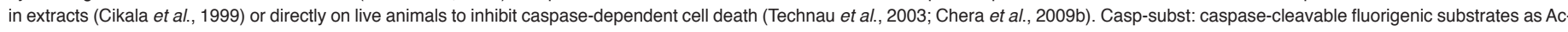

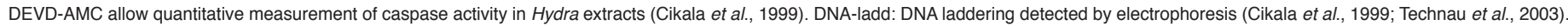

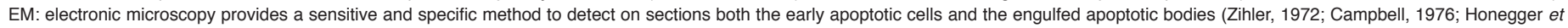

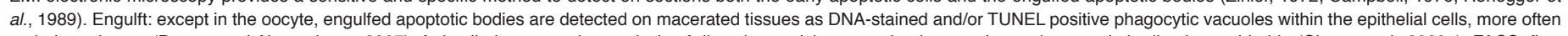

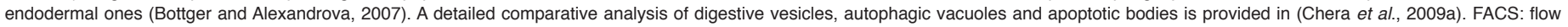

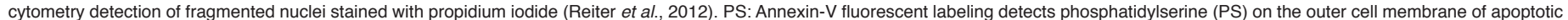

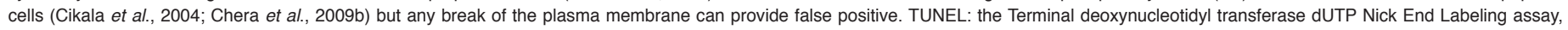

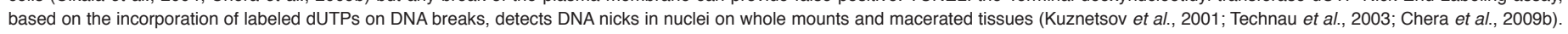

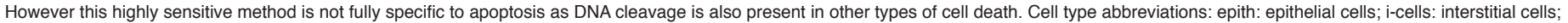
nb: nematoblasts; nc: nematocytes; nv: nerve cells; gl: gland cells. 
lost in the following days, providing "nerve-free" or "epithelial" animals. This experimental framework, which is similar although not identical to that provided by the animals exposed to pro-apoptotic drugs (Terada et al., 1988), was quite useful, as for instance to follow the cycling behavior of the epithelial cells (Holstein et al., 1991 ) or to assess the lineage restriction of transcription factors involved in neurogenesis (Gauchat et al., 2004; Lindgens et al., 2004; Miljkovic-Licina et al., 2007).

The kinetics of this heat-inducible cell death process was investigated on macerated tissues (Marcum et al., 1980; Terada et al., 1988). Both studies found a rapid disappearance of the interstitial stem cells (large and small) during the first 16 hours of the heat shock, with clear hallmarks of phagocytosis reported by Terada et al., who used Feulgen staining. When sf-1 polyps were $A O$ and DAPI stained 6 hours after heat-shock, then indeed the nuclei of the AO positive cells exhibited a typical pycnotic morphology, confirming that apoptosis is the main mechanism involved in the early phase of heat-shock induced cell death (Cikala et al., 1999).

However among the other cell types that remain intact during that early phase, the nematoblasts got eliminated later, between 16 and 48 hours of heat-shock, with a limited contribution of phagocytosis during that late phase (Terada et al., 1988). Indeed when measuring the proportion of epithelial cells with engulfed bodies, Terada and colleagues found that the phagocytosis rate was low ( 0.14 phagocytosed cell per epithelial cells) and could not account for all cell losses. They thus suggested that another uncharacterized mechanism might contribute to the elimination of i-cells, either necrosis or extrusion of dying cells into the gastric cavity. Similarly Marcum and colleagues who used electronic microscopy had actually reported about the lack of phagocytosis at 24 hours heat-shock but the presence of "degenerating interstitial cells". They had thus proposed a self-disintegration process distinct from phagocytosis. Therefore two successive mechanisms might apply in this heat-shock context, an early apoptotic one for the immediate death of the i-cells, and a later one, still uncharacterized for the death of the nematoblasts.

\section{Pharmacological-induced cell death: colcemid, colchicine, wortmannin}

Irradiation of Hydra had shown the deleterious effect of X-rays on the interstitial but not on the epithelial cell lineages, with animals losing quickly their interstitial stem cells but keeping intact their epithelial cells and exhibiting for several days the capacity to bud and regenerate (Strelin, 1929; Brien and Van Den Eeckhoudt, 1953). The first observation of cell death in Hydra came from Dick Campbell in 1976, who noticed a massive loss of interstitial cells, nematoblasts, nematocytes and nerve cells in animals that had been exposed to the cytostatic agent colchicine (Campbell, 1976). When he investigated these cellular modifications at the ultrastructural level, he noted that these cells were actually engulfed by the endodermal epithelial cells. Several years later DAPI staining indeed showed the typical fragmentation of nuclei in animals exposed to colchicine, confirming thus that the hallmarks of apoptosis in Hydra were similar with those observed in higher metoazoans (Cikala et al., 1999). Hence the dying cells in Hydra have a roundish shape with condensed nuclear DNA, rapidly degraded in smaller fragments of nucleosome size, finally forming apoptotic bodies that get engulfed by their neighboring epithelial cells.
Beside colchicine, colcemid or irradiation, exposure to the phosphatidyl inositol 3-kinase (PI3K) inhibitor wortmannin (David et al., 2005) or to cytotoxic agents as 4-nonylphenol can efficiently induce apoptosis in Hydra (Pachura et al., 2005). Similarly to colchicine, wortmannin rapidly induces apoptosis of most interstitial cell types without affecting the epithelial cells (see below).

\section{Wound-induced cell death}

In 1984 Fujisawa and David reported about a selective form of cell death, affecting exclusively the differentiating nematocytes, more specifically the stenotele and desmoneme precursors, two out of the four types of nematocytes present in Hydra (Fujisawa and David, 1984). This transient cell death was initially observed in tissues from Hydra body column after removing the apical and basal regions, with as in other contexts, apoptotic bodies engulfed by the epithelial cells. But it was also noted in tissues of wounded animals implying that this injury-induced apoptosis is not linked to the regeneration process per se but more likely a consequence of the diffuse effect of toxic substances released upon injury.

\section{Injury-induced apoptosis and compensatory proliferation}

More recently a systematic analysis of the cellular remodeling occuring in the regenerating tips evidenced a massive wave of apoptosis in the head-regenerating tips (about $100 \mu \mathrm{m}$ thick), affecting cells from the interstitial lineage (Chera et al., 2009b; Galliot and Chera, 2010; Chera et al., 2011). Indeed immediately after mid-gastric amputation, neurons, nematocytes, gland cells and progenitors located in the vicinity of the bisection plane in the head regenerating tips were found apoptotic when detected with TUNEL, Hoechst or Annexin-V. The quantification of this localized cell death showed that $50 \%$ of the cells, all from the interstitial cell lineage, die and are subsequently engulfed by the endodermal epithelial cells. The activation of the MAPK/CREB pathway is required for this asymmetric wave of apoptosis as evidenced by its inhibition by RNAi of the RSK, CREB and CBP genes or exposure to U0126 that all prevents apoptosis and head regeneration. Surprinsingly cells with typical apoptotic figures at the early stage of the process were found strongly positive for Wnt3, suggesting that these cells transiently release Wnt3, which in turn activates the b-catenin pathway in the adjacent cycling progenitor cells and induces their rapid mitotic division. Thus apoptosis in this context seems to provide a direct link between injury and activation of the head-regeneration program through synchronization of cell division. In contrast, the level of apoptosis was very low in the foot regenerating part, highlighting the immediate asymmetric response to injury between the two animal halves. Interestingly apoptosis-induced compensatory proliferation now appears as a widely used process across evolution to launch a regeneration program (Bergmann and Steller, 2010).

\section{Cell death in heterografts}

While performing grafts between $H$. vulgaris and $H$. oligactis, Lin et al., noticed an increased number of epithelial cells with phagocytic vacuoles at the boundary zone of the heterograft (Lin et al., 2000). In such grafts, cells from one species are removed specifically by phagocytosing cells of the other species. Further investigations using TUNEL and $A O$ stainings evidenced the presence of apoptotic cells at the contact zone, affecting more 
extensively $H$. vulgaris than $H$. oligactis cells (Kuznetsov et al., 2002). These authors also noted impaired interactions between epithelial cells and the extracellular matrix and suggested that cell detachment plays the primary role in the induction of this type of cell death (anoikis). However the cell types affected by this process are not known and the signals linked to cell detachment as well as the responses they trigger in each species, confering sensitivity or not to cell death remain to be identified.

More generally the same questions arise in each context where cell death is observed in Hydra: 1) What signals, what pathways are used to trigger cell death in a given context? 2) What makes cells sensitive or resistant to these signals? 3) In the context of head regeneration, does apoptosis-induced compensatory proliferation rely on non-apoptotic functions of caspase(s)? 4) What are the pathway/signals that regulate the choice between apoptotic and non-apoptotic functions of caspases? 5) How much of these regulations was submitted to evolutionary constraints and thus maintained across metazoan or eumetazoan evolution? How much does correspond to species- or phylum-specific variations? Very few is currently known concerning each of these questions. Here we will first briefly review the components of the Hydra apoptotic machinery as detailed reports were recently published on this question (Lasi et al., 2010a; Lasi et al., 2010b). Then we will discuss some strategies that provide comparative molecular and cellular analyses of apoptotic processes in Hydra.

\section{Conservation of the apoptotic machinery from Hydra to mammals}

Classically cell death can be triggered either by the intrinsic mitochondrial pathway or by the extrinsic death receptor pathway and indeed, the studies performed over the past 12 years have demonstrated the evolutionary conservation of both pathways in the freshwater polyp Hydra (Cikala et al., 1999; David et al., 2005; Lasi et al., 2010a; Lasi et al., 2010b). As part of the genetic repertoire of the apoptotic machinery seems to have been lost in ecdyzozoans but conserved in cnidarians (Lasi et al., 2010b), Hydra provides a well suited position to trace back the early functions and regulations of the apoptotic pathways in eumetazoans.

\section{Conservation of the intrinsic apoptotic pathway}

In mammals activation of the intrinsic apoptotic pathway results primarily from activation of the proapoptotic members of the B-cell lymphoma protein-2 (Bcl-2) family. The mitochondrial integrity is regulated by the activity of the Bcl-2 proteins that are subdivided into three subclasses according to their pro- or anti-apoptotic action and the $\mathrm{Bcl}-2$ Homology $(\mathrm{BH})$ domains they possess: i) the anti-apoptotic proteins Bcl-2, Bcl-XL, Bcl-w, Mcl-1, A1/Bfl-1, ii) the pro-apoptotic Bax, Bak, Bok/Mtd, both classes harboring four $\mathrm{BH}$ domains, iii) the pro-apoptotic "BH3-only" proteins that possess only the BH3 domain as the Bid, Bim/Bod, Bad, Bmf, Bik/Nbk, Blk,

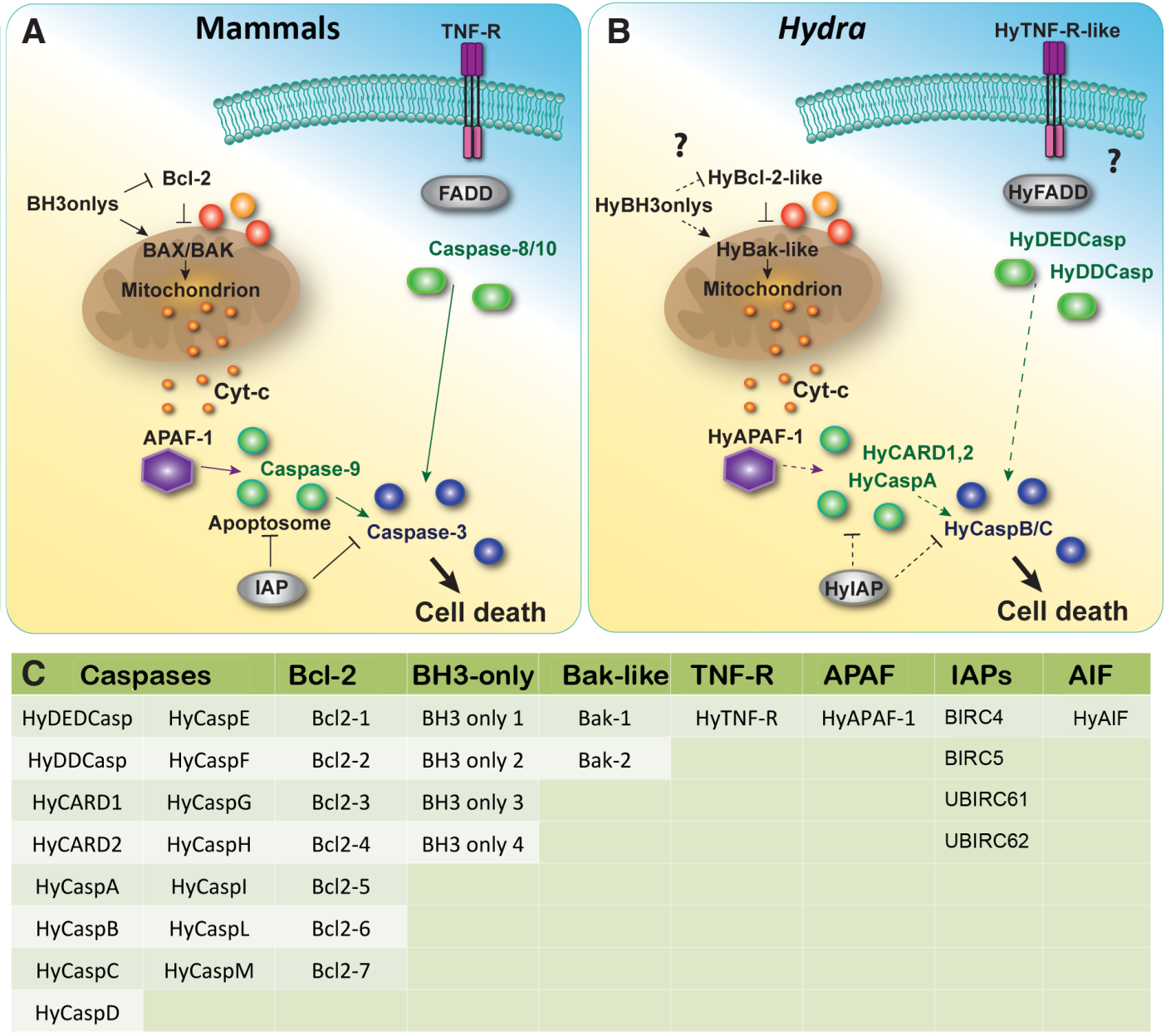

Fig. 2. Conservation of the apoptotic machinery in Hydra. Schematic representation of the apoptotic pathways in mammals(A) and Hydra (B). In mammals the cell death machineryis divided in extrinsic (blue background) and intrinsic (yellow background) pathways. (B) In Hydra both pathways are predicted (Cikala et al., 1999; David et al., 2005; Lasi et al., 2010a; Lasi et al., 2010b). The question marks indicate the putative formation of complexes between components as anticipated from those identified in mammals. Similarly the dashed lines indicate protein interactions not tested experimentally yet in Hydra. (C) List of the components of the Hydra apoptotic pathways deduced from genomic and cDNA analyses, adapted from (Lasiet al., 2010a). Concerning the inhibitor of apoptosis (IAPS) the BIRC nomenclature is used here: BIRC4 (or hylAP) contains 3 Baculovirus IAP repeat (BIR) domains and one RING domain, BIRC5 (also named survivin) contains a unique $B I R$ domain; BIRC6 (named Bruce in mouse, apollon in humans and dBruce in Drosophila) also contains a unique BIR domain and an Ubiquitin-conjugating catalytic

(UBCC) domain. In Hydra the two BIRC6-related proteins miss the BIR domain, therefore we named them UBIR61 and UBIR62. 
Noxa, Puma/Bbc3, and Hrk/DP5 proteins (Degterev and Yuan, 2008; Martinou and Youle, 2011). BH3-only proteins interact with anti-apoptotic proteins to inhibit their function but additionally they are able to interact with multi-domain proteins such as Bax and Bak to activate and stimulate their pro-apoptotic function. The analysis of the Hydragenome identified seven predicted anti-apoptotic $\mathrm{Bcl}-2$ like proteins, four BH3-only proteins and two proteins with Bak-like domains (Chapman et al., 2010; Lasi et al., 2010a).

In mammalian cells, permeabilization of the mitochondrial outer membrane (MOM) and the subsequent fission of the mitochondria leads to the release of cytochrome $c$ and many other proteins from the mitochondrial intermembrane space. In the cytosol, cytochrome c, together with APAF1 and dATP participates in the formation of the apoptosome, a macromolecular platform required for the activation of caspase 9 (Martinou and Youle, 2011). However a similar sequence of events is not proven yet in invertebrates, i.e. in C. elegans and Drosophila where there is evidence neither for MOMP nor for cytochrome c release.

In Hydra a typical APAF1 protein is expressed (Lasi et al., 2010a). Moreover most Bcl2-like proteins and the two Bak-like proteins were found at the mitochondria whereas the Bcl-2-4 and Bak1 proteins potentially interact as shown in a yeast two-hybrid assay (Muller-Taubenberger et al., 2006; Lasi et al., 2010b). When overexpressed in the mammalian HEK293 cells, most Hydra proteins regulate apoptotic activity as anticipated from their structure: the two Bak-like proteins behave as strong apoptosis inducers, six of the seven $\mathrm{Bcl}-2$ proteins can inhibit camptothecin-induced apoptosis, but among the four BH3-only proteins, only BH3-only 3 can promote apoptosis (Lasi et al., 2010b). However as in C. elegans and Drosophila, there is no proof yet that cytochrome c is released during apoptosis. Further experiments should reveal soon how the intrinsic pathway is activated in Hydra.

\section{Conservation of the extrinsic apoptotic pathway}

The extrinsic pathway is mediated by the extra-cellular stimulation of the death receptor (DR) family that induces the formation of the death inducing signaling complex (DISC) at the cytoplasmic side of the death receptor. Hydra indeed express a homolog to the Tumor Necrosis Factor Receptor (TNF-R) with, as well characterized DR domains, a characteristic extracellular TNF-R domain and a cytoplasmic Death Domain (DD) (Lasi et al., 2010a). The ortholog of the adaptor protein Fas-Associated Death Domain (FADD), which connects the receptor to caspase 8 or 10, also exists in Hydra (Fig. 2A)

In contrast, the presence of other critical members of the complex like the Receptor-Interacting Protein (RIP) kinases RIP1 and RIP3 remains unclear. These kinases take part in the formation of the apoptotic macromolecular platform leading to the activation of caspases or guide the activation of necrosis in the presence of caspase inhibition (Darding and Meier, 2012). Indeed among the recent findings concerning the regulation of programmed cell death is the discovery of the ripoptosome in mammals, a death receptor/ ligand independent macromolecular platform build up by the core components RIP1, caspase-8 and FADD. These components spontaneously form together upon depletion of the cytoplasmic Inhibitor of Apoptosis Protein (IAP) in response to genotoxic stress (Feoktistova et al., 2011; Tenev et al., 2011). Up to now it remains unknown whether the formation of macromolecular platforms similar to the apoptosome (Zou et al., 1999) or the mammalian ripoptosome contributes to the regulation of cell death in Hydra.

\section{Structural and functional analysis of Hydra caspases}

Activation of the apoptotic pathway in Hydramay proceed through an extrinsic or intrinsic pathway as previously discussed. A closer look at the numerous caspases present in Hydra shows that up to 15 caspase sequences harbor active site residues including cysteine and histidine residues (Fig. 2B). Potential caspase cleavage sites between the large and small subunits are conserved as well as the substrate pocket in the small subunit. Another indication of an active intrinsic and extrinsic apoptotic pathway in Hydra is the presence of putative initiator caspases with the typical CARD, DED and an unusual DD domain for metazoan caspases in its prodomain (Cikala et al., 1999; Lasi et al., 2010a). However no autocleavage activity was detected for the caspases possessing the CARD or DED domains when expressed in E.coli. By contrast two Hydra caspases that do not contain a CARD domain and are therefore not expected to possess auto-processing activity (as deduced from mammalian initiator caspases) exhibit autoprocessing activity: HyCaspA whose activity can be abolished by the pan-caspase inhibitor ZVAD, and HyDDCasp sensitive to the inhibitor Ac-YVAD-CHO suggesting a substrate specificity similar to Caspase 1 (Lasi et al., 2010b).

How is it possible to directly assess the functionality of caspases in Hydra? Previous studies showed that extracts of apoptotic Hydra as well as in vitro produced Caspase $B$ and Caspase $C$ efficiently cleave the DEVD motif that is also cleaved by the mammalian caspases 3 and 7 (Cikala et al., 1999; Lasi et al., 2010b). Similarly we show here (see Fig. $3 \mathrm{C}$ ) that extracts from wortmannin-treated Hydra efficiently cleave the Drosophila IAP1 cleaveage site DQVD, a site for the effector caspases Drice and Dcp1 (Bardet et al., 2008). These results indicate that effector caspases recognize the same cleavage sites from Hydra to bilaterians, represented here by mammals and Drosophila. Further studies are necessary to assess the activities of the predicted initiator caspases in Hydra but the highly homologous DED domains of HyDEDCasp and mammalian caspase-8 indicate that HyDEDCasp could act as an initiator caspase of the extrinsic pathway. All together these results suggest that caspases in Hydra could well be divided into initiator and effector caspases, as in mammalian cells. However further studies are required to assess the substrate specificities of these caspases and their diverse biological functions.

\section{Conservation of caspase inhibitors, BIRC4, BIRC5, BIRC6 and VIAF}

Inhibitors of apoptosis (IAPS) are characterized by the presence of at least one Baculoviral IAP Repeat (BIR) domain: BIR domains that are dedicated to protein-protein interactions are conserved from yeast to bilaterians where they can directly inhibit caspases (Srinivasula and Ashwell, 2008; Darding and Meier, 2012). Mammals express eight distinct families of BIR containing proteins (BIRC), which differ by the number of BIR domains and the different associated domains they contain. BIRC2, BIRC3, BIRC4 (also named c-IAP1, c-IAP2, XIAP respectively), contain three BIR domains, one Ubiquitin Associated (UBA) domain and one Really Interesting New Gene (RING) domain with Ubiquitin E3 ligase activity; BIRC2 and BIRC3 also include a CARD domain. In Drosophila the BIRC4 ortholog DIAP2 shares the same structure whereas DIAP1 contains only 2 BIR, one RING but no UBA domains (Darding and Meier, 
2012). These inhibitors likely regulate the activity of the ripoptosome in mammals or the apoptosome in Drosophila, specially the BIRC4 proteins. A BIRC4-like gene (hylAP) was identified in Hydra, encoding three BIR and one RING domains (Lasi et al., 2010a) but no UBA domain.

Two other BIRC gene families that contain a single BIR domain are expressed in Hydra, the short BIRC5 (also named survivin) and the giant BIRC6 gene (also named Bruce). In addition to the BIR domain located at the N-terminus that inhibits caspase activity (Bartke et al., 2004), BIRC6 proteins also contain at their C-terminus a Ubiquitin conjugating E2/E3 enzyme activity (UBC) domain that leads to the degradation of apoptosis activators as reaper in Drosophila (Vernooy et al., 2002; Domingues and Ryoo, 2011). Both the BIR and UBC domains are responsible for protecting the cells against apoptosis (Bartke et al., 2004), and upon ubiquitination and degradation of BIRC6, inhibition of apoptosis is releaved (Qiu et al., 2004). Hydra and Nematostella each contain BIRC6-type genes that encode a highly conserved UBC domain but no BIR domain (BG, unpublished). Given the role of this UBC domain in the regulation of apoptosis, independently of the BIR domain, one might anticipate a similar role for the cnidarian BIRC6related proteins.

In addition BIRCs carrying the E3 ligase activity mediate the regulation of biological processes ranging from cell survival, cell proliferation and cell death thanks to the ubiquitin-dependent modulation of NF-kB signaling. In Hydra innate immunity relies on NF-kB activation (Augustin and Bosch, 2011) and it would be interesting to know whether BIRC4 or BIRC6 regulate both cell death and immunity in Hydra.

Hydra as Nematostella also express BIRC5 (survivin), a short protein with a single BIR domain and a nuclear export signal but no RING domain. Thanks to its association with microtubules, survivin plays a dual role to promote cell survival, in the nucleus linked to kinetochores it preserves microtubule integrity and supports chromo-

Fig. 3. Biochemical measurements of apoptotic activity. (A) Detection of caspase activity in $50 \mu \mathrm{g}$ whole cell extracts (WCE) prepared from Hydra vulgaris exposed to Wortmannin for 5 hours at variable concentrations $(0.5,1,1.5 \mu \mathrm{M})$. Upon cleavage the DEVD-AMC caspase substrate (ENZO Life Sciences) emits fluorescence read on a Victor X5 Fluorescent plate reader (Perkin Elmer). The same reaction was measured successively four times in 25 min intervals. (B) Scheme of the Apoliner constructs kindly provided by (Bardet et al., 2008). The caspase cleavage site from the Drosophila DIAP1 protein (arrowhead) separates the MCD 8 and mRFP coding sequences from the nuclear localization signal and eGFP sequences. Two versions were produced, either containing a wild-type caspase cleavage site (Aposensor) or a mutated one (Apomut, no shown). BIR: Baculoviral IAP repeat. (C) For the in vitro cleavage assay $50 \mu \mathrm{g}$ WCE prepared from Wortmannin-induced Hydra (as in A) were incubated with $5 \mu /$ Aposensor protein produced in reticulocyte lysate. The mixtures Aposensor-WCEs and Apomut-WCEs were then loaded on PAGE for Western blot analysis. The cleaved and uncleaved fragments were detected with two different antibodies, either recognizing the DIAP protein immediately downstream to the cleavage site (left panel), or detecting the eGFP epitope (right panel). The loading was controlled with the $\alpha$-tubulin antibody. some segregation, in the cytoplasm it prevents caspase activation once phosphorylated. Recently the poriferan BIRC5 was shown to promote both activities, i.e. cell division and apoptosis inhibition, when expressed in mammalian cells (Luthringer et al., 2011). Finally cnidarians including Hydra also express an evolutionarily conserved inhibitor of IAP named VIAF for viral IAP-associated factor (Wilkinson et al., 2004) that belongs to the phosducin-like protein family.

\section{Six putative regulators of cell death conserved from Hydra to human}

Recently six novel putative regulators of cell death were identified in a RNA-seq reference transcriptome of Hydra vulgaris (Wenger and Galliot, unpublished). These proteins CD38, JTB, MRLP41, NLRP3, NISCH and RFFL were identified in reciprocal blast hits thanks to their high similarity with their human cognates. The multifunctional cell surface CD38 protein can promote apoptosis and the loss of CD38 expression is used as a marker of cancer stem cells in Acute Myeloid Leukemia (Fulda and Pervaiz, 2010). In mammals the Jumping translocation breakpoint (JTB) protein localizes to the mitochondria and promotes resistance to TGFb1induced apoptosis (Kanome etal., 2007). The MRLP41 protein likely plays an anti-apoptotic role as it contributes to chemoresistance when up-regulated as in T-cell Acute lymphoblastic leukemia (TALL) patients that harbor a 9q34 translocation with amplification of the region containing this gene (van Vlierberghe et al., 2006). The Nucleotide-binding domain and Leucine rich Repeat containing family with pyrin domain containing 3 protein (NLRP3) is a member of the nucleotide-binding oligomerization domain (NOD)-like receptors that constitute the inflammasome platform. In human cells

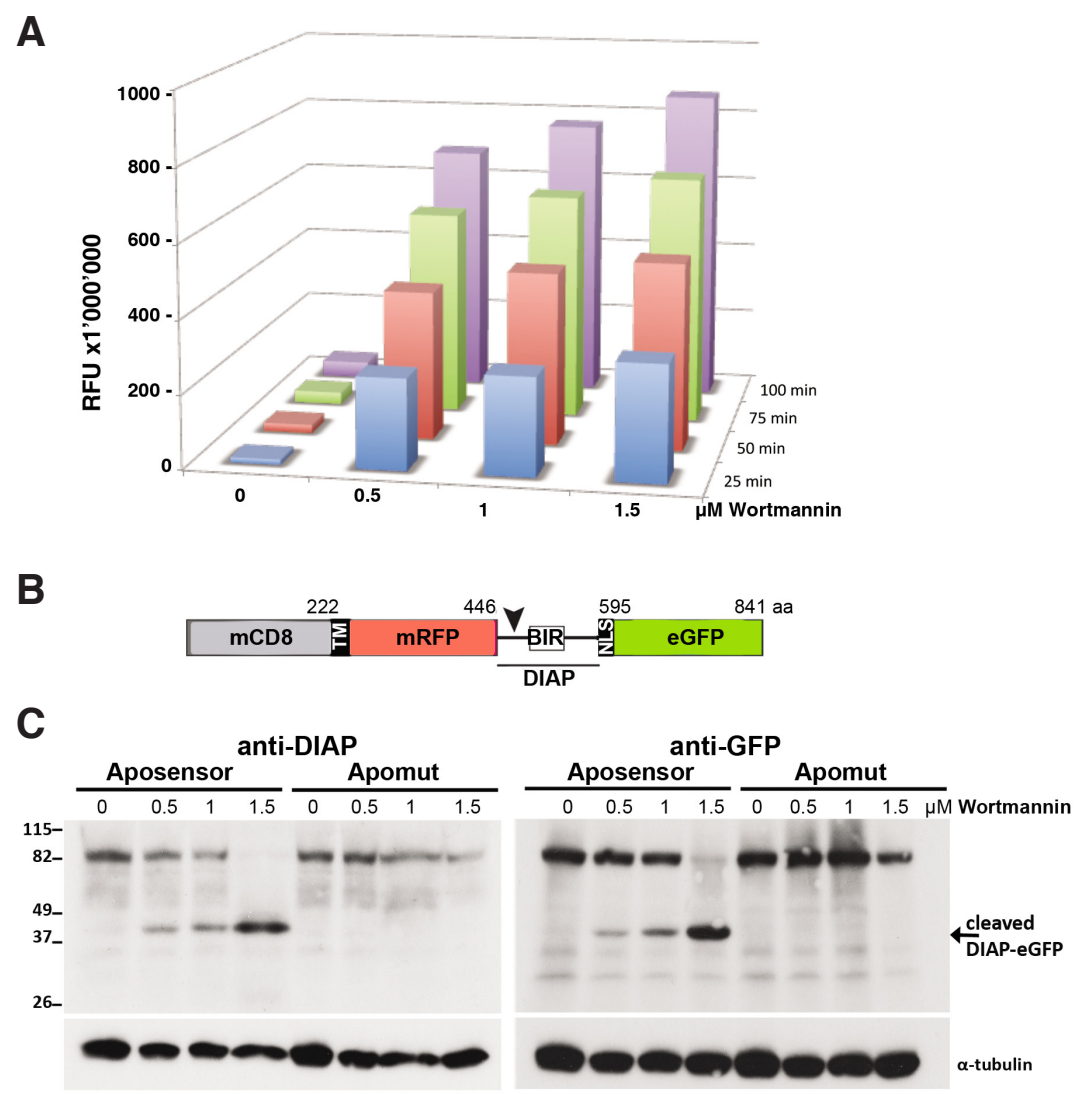


NLRP3 can activate inflammatory caspases but it may also act as an inducer of apoptosis by regulating NFkB signaling (O'Connor et al., 2003). NOD-like receptors containing NACHT and NB-ARC domains (NLRP1) were recently identified in cnidarians, likely acting as activators of caspases involved in the innate immune response (Lange et al., 2011). Finally the Nischarin protein (NISCH), or imidazoline 1 receptor acts as an anti-apoptotic protein possibly by up-regulating the PI3K pathway (Dontenwill et al., 2003). Similarly the E3 ubiquitin-protein ligase rififylin (RFFL) that contains a FYVE domain and a RING domain, also exhibits an anti-apoptotic activity in mammals by down-regulating the levels of Caspases 8 and 10 (McDonald and El-Deiry, 2004). Thus, these proteins are possibly involved in apoptotic as well as non-apoptotic cell death mechanisms (Degterev and Yuan, 2008) and Hydra provides a fruitful experimental framework to test these distinct functions.

\section{Biochemical monitoring of apoptotic activity in Hydra}

To monitor quantitatively the caspase activity in different contexts, we applied to Hydra two distinct types of biochemical assays. In both cases, we measured the caspase activity present in whole cell extracts prepared from Hydraexposed to pro-apoptotic drugs or not. In the first assay we detected by fluorimetry the specific cleavage of the DEVD substrate by these extracts, and in the second we used an Aposensor protein to visualize on Western analysis the proportion of cleaved protein (Bardet et al., 2008).

\section{Caspase cleavage of fluorogenic substrates}

David and colleagues previously showed that one can gradually induce apoptosis in Hydra by exposing the animals to increasing concentrations of the Pl-3 kinase inhibitor wortmannin (David et al., 2005), as evidenced by counting the number of apoptotic cells stained by DAPI and TUNEL on macerated tissues. This method is highly reliable but time-consuming. The use of the AcDEVD-AMC fluorogenic substrate is a well established method to quantify apoptosis and was already applied in Hydra to measure apoptosis activity 24 hours after colchicine exposure (Cikala et al., 1999). Thus we assumed that measuring Ac-DEVD-AMC cleavage activity in whole cell extracts (WCE) might provide a sensitive and fast assay to compare caspase activities in different contexts. Practically we induced apoptosis by exposing Hydra for 5 hours to various concentrations of wortmannin ranging from 0.5 to $1.5 \mu \mathrm{M}$. We then prepared for each condition WCE as in (Kaloulis et al., 2004), incubated $50 \mu \mathrm{g}$ WCE with the Ac-DEVD-AMC fluorogenic substrate and measured every $25 \mathrm{~min}$ the fluorescent release on a fluorescent plate reader (Fig. 3A). The four measurements performed over 100 minutes showed that caspase activity accumulates over time but also increases with higher concentrations of wortmannin. The non-treated extracts do not show any significant increase in apoptotic activity within the first 100 min of incubation, which proves that the substrate itself does not contribute to the fluorescent signal. The potential of the assay lies in the quantification of the specific cleavage activities of the different caspases in Hydra. Furthermore, this assay can be combined with cellular and biochemical methods to extend the analysis of cleavage activities to well-defined biological contexts.

Caspase cleavage of chimeric proteins, the Aposensor tool To study in depth the cell death processes in Hydrathere is a need to develop tools that allow the analysis of cellular behavior through live imaging as well as the analysis of biochemical processes. Such tools were already developed in other model organisms as Drosophila and JP Vincent and P. Bardet kindly made available to us the Apoliner constructs they had designed to investigate the regulatory mechanisms that control apoptosis in developing and adult flies (Bardet et al., 2008). Apoliner is a caspase sensor chimeric construct that encodes two fused fluorescent proteins, in the $\mathrm{N}$-moiety $\mathrm{mRFP}$ with a transmembrane site and in the $\mathrm{C}$-moiety eGFP with a nuclear localisation signal. These two proteins are linked by a caspase cleavage site (DQVD) taken from the apoptosis inhibitor DIAP1 and located in front of a BIR domain that enhances recognition by caspases (Fig. 3B). As a consequence cleavage by the Drosophila effector caspases Drice and Dcp1 is efficient and takes place very early in the apoptotic process. As control they designed a mutated form of the Aposensor, named Apomut, with a single point mutation in the caspase cleavage site (DQVA). Cleavage of Aposensor can be detected in vivo as in the presence of active caspases, the NLS-eGFP moiety is released and translocates to the nucleus. Cleavage can also be detected biochemically with detection of the cleaved fragments by Western blot.

To apply this elegant system to Hydra, we first studied whether it was sensitive to the endogenous activation of Hydra caspases. For that purpose we induced cell death by treating the animals with wortmannin for 5 hours at various concentrations, ranging from $0.5 \mu \mathrm{M}$ to $1.5 \mu \mathrm{M}$. We then prepared WCEs and incubated them in the presence of either Aposensor or Apomut proteins that had been previously in vitro transcribed. The cleavage reaction was carried out at room temperature for $5 \mathrm{~min}$ and the mixtures WCE-Aposensor / WCE-Apomut were then applied on PAGE for western detection. The cleaved fragments were detected with two different antibodies, one recognizing eGFP and the other detecting DIAP downstream to the cleavage site (Ribeiro et al., 2007). Both antibodies successfully detected the uncleaved and the cleaved fragments; furthermore Apomut (mutated site) was not cleaved in apoptotic conditions proving that Hydra proteases, possibly caspases specifically recognize the DQVD motif (Fig. 3C). Cleavage could still be observed for the lowest concentration indicating a comparable sensitivity to the DEVD-AMC substrate cleavage assay. Note that in non-apoptotic conditions Apoliner is not cleaved, proving that Apoliner by it-self does not affect apoptotic activity that remains undetectable in homeostatic conditions as previously shown (Bottger and Alexandrova, 2007; Chera et al., 2009b). All together this biochemical analysis of Apoliner as an aposensor is promising for further applications in Hydra. However when tested in conditions where apoptosis is either less massive or more spatially limited, i.e. with extracts from heat-shocked sf-1 animals or from head regenerating animals, we could not detect any cleavage (data not shown). Therefore sensitivity might be the limit of this aposensor biochemical detection and Apoliner or any other similar aposensor needs now to be expressed in live Hydra tissues, specially interstitial cells, to monitor caspase activity.

\section{Cellular monitoring of apoptotic activity in Hydra}

\section{Flow cytometry monitoring of apoptosis}

As previously reported apoptotic cells in Hydracan be characterized and quantified on maceration tissues thanks to DNA staining combined to TUNEL staining, a widely used in situ method to 
identify DNA fragmentation induced upon activation of the apoptotic pathway (see Table 1). However when cell death is advanced cell types can no longer be recognized but the apoptotic cell types can be deduced and quantified from the surviving cells (Chera et al., 2009b). This is efficient and precise but time-consuming. Also the TUNEL assay is not specific to apoptosis as any severe or unspecific DNA damage, including other forms of cell death, provide a positive labeling although not corresponding to apoptotic cells. Therefore the typical kinetics of apoptosis, i.e. the early DNA fragmentation, needs to be confirmed by other methods.

To provide a fast and quantitative method to monitor the kinetics of cell death, we measured DNA fragmentation by flow cytometry (FACS). Indeed DNA degradation can be monitored by flow cytometry after DNA staining with nuclear dyes. Among them, propidium iodide (PI) is widely used as a DNA dye to measure the cell cycle profiles and DNA degradation in mammalian cells. We thus established a method to assess both cell cycling pattern and DNA fragmentation in Hydra based on combined hypertonic-enzymatic tissue dissociation, followed by detergent permeabilization and nuclear staining with PI (WB, unpublished). Thanks to this method we can quantify DNA degradation after induction of apoptosis using a logarithmic amplifier of PI fluorescence (Fig. 4B).

As oogenesis provides a context where apoptosis is highly synchronized with the maturation of the gonad, we submitted to FACS analysis dissected body column regions that contain gonads from females of the AEP strain at various stages of oogenesis (Fig. 4A). As previously described oogenesis starts with the accumulation and the proliferation of a germ-restricted interstitial cells underneath the ectoderm (stage 1-3), then nurse cells differentiate (stage 3) and start to undergo apoptosis, a process that will pause when the oocyte enlarges and finally gets mature (stage 5-7). Flow cytometric monitoring of DNA content during oogenesis confirmed the earlier microscopic data as evidenced by the significant increase in the proportion of G2 cells in stage 3 egg-patch, when most of the germ cells have a tetraploid DNA content (Miller et al., 2000; Alexandrova et al., 2005). From stage 3 onwards, when these tetraploid germ cells differentiate in nurse cells, the flow cytometric measurements also showed a high number of debris, corresponding to the initiation of DNA degradation process when nurse cells enter apoptosis. Then the proportion of debris increased slowly, but nevertheless, the extent of DNA fragmentation remained limited as nurse cells undergo a partial apoptosis. We also noticed a distinct cell cycle pattern after the onset of apoptosis in stage 5, that could be related to the presence of apoptotic nurse cells that display a DNA content with less than $4 \mathrm{n}$ after apoptosis induction.

That way we identified large areas (noted as debris on Figures 4 and 5) that contain the cells with degraded DNA and/or apoptotic bodies. This area, which also includes necrotic cells, chromosomes or debris, is located in front of the DNA histogram of the cells that have an undamaged DNA content (between $2 n-4 n$ ). Therefore this fraction only indicates the extent of DNA damage and should not be interpreted as apoptotic. By contrast the analysis performed on ethanol fixed mammalian cells after PI labeling evidenced a clear, sharp apoptotic peak located in front of the G1 fraction,

A

B due to the leakage of DNA fragments with low molecular weight (Ormerod, 2000). However this work was performed in cell culture conditions and not tissues as in Hydra where the cell complexity is much higher. Also in Hydra, we use a procedure that involves detergent permeabilization but no ethanol fixation, and this might explain the absence of the sharp peak with apoptotic DNA content. Therefore an apoptotic index cannot be deduced from these data although we show here that flow cytometry provides a reliable and quantitative method to measure DNA degradation and indirectly assess apoptosis. As usually advised, flow cytometry evidences of apoptosis should be confirmed by microscopy methods to identify the apoptotic cells (Ormerod, 2000).

\section{Comparative analyses of drug-induced and heat-shock in- duced apoptosis}

To compare two distinct contexts where apoptosis is induced in Hydra, we used animals from the thermosensitive sf-1 Hydra strain that were either exposed to wortmannin or submitted to heat-shock. We then monitored the extent of cell death by TUNEL on macer-
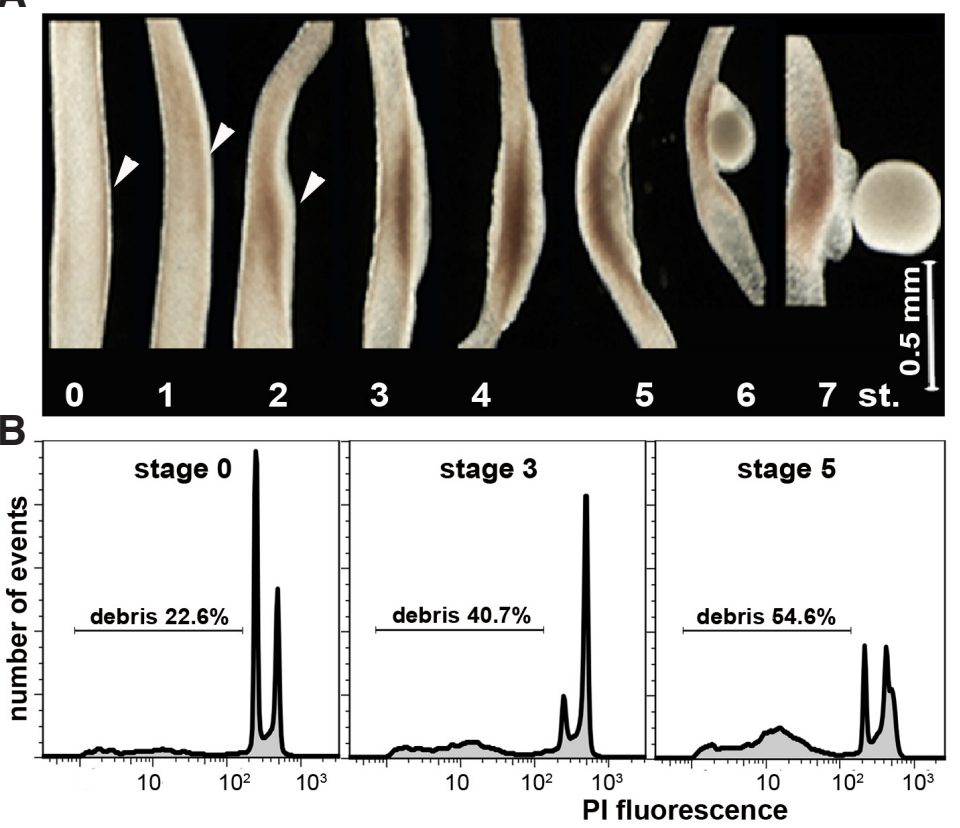

Fig. 4. Flow cytometry analysis of cell death in nurse cells during oogenesis. (A) Ovary formation and oogenesis in the AEP sexual strain: Oogenesis in Hydra starts with the accumulation and aggregation of an egg-restricted interstitial cell population underneath the ectoderm (stage 1). This egg-patch progressively grows during the next 2 stages, consisting then in thousands of proliferating and differentiating germ cells. At stage 3, when the egg-patch displays a milky spot appearance, $90 \%$ of these germ cells have a pre-meiotic 4N DNA content. Among these pre-meiotic cells, a single one enters meiosis, while the others, under the influence of the oocyte, differentiate in nurse cells. From stage 3 onwards, these nurse cells undergo partial apoptosis and transfer their cytoplasm into the developing oocyte (Miller et al., 2000; Technau et al., 2003; Alexandrova et al., 2005). The oocyte continues to increase in volume (stage 5) by phagocytosing the surrounding apoptotic nurse cells and finally contracts its pseudopodia to take a round shape and complete meiosis (stage 6 and 7), being ready for fertilization. (B) Cell cycle profiles in female polyps taken at stage 0, stage 3 and stage 5 of egg-patch development. FACS analyses were performed on the dissected part of the body column that contain the developing oocyte. Note the significant increase in cell debris at stages 3 and 5, when DNA fragmentation occurs in the nurse cells. 
ated tissues and by flow cytometry on dissociated cells (Fig. 5). The animals treated with $0.5 \mu \mathrm{M}$ wortmannin for 8 hours showed a large number of TUNEL positive cells that all belonged to the interstitial cell lineage: interstitial cells, nematoblasts, nematocytes, nerve and gland cells. In addition, we noticed a number of epithelial cells, ectodermal and endodermal, that contained TUNEL positive phagocytic vacuoles as a result of the engulfment of the apoptotic bodies by these epithelial cells (Fig. 5 A,B).

By contrast the number of TUNEL positive cells in the heatshocked animals remained low during the first 24 hours of heat-shock with few TUNEL positive interstitial cells displaying fragmented apoptotic nuclei (Fig. 5D). In fact most TUNEL positive cells corresponded to epithelial digestive cells that had engulfed apoptotic bodies (Fig. 5E). These cells also contained numerous vacuoles strongly labeled by TUNEL although poorly stained for DNA. These second type of vacuoles likely correspond to apoptotic bodies already highly degradated. These results confirm previous studies showing that cells of the interstitial lineage rapidly undergo apoptosis upon heat-shock and get engulfed by the epithelial cells (Terada et al., 1988; Cikala et al., 1999).
In both contexts we noted a good correlation between the level of DNA fragmentation evidenced by flow cytometry with that observed after TUNEL staining (Fig. 5 F-I). However flow cytometry that allows quantification of DNAdamage showed clear differences between wortmannin-induced and heat-shock induced apoptosis: In wortmannin-treated animals the number of cell debris was doubled after 8 hours exposure, reflecting the on-going DNA fragmentation (Fig. $5 \mathrm{~F}, \mathrm{G}$ ) whereas a much more limited increase in the number of cell debris was observed after a two days heat-shock (Fig. 5 $\mathrm{H}, \mathrm{I})$. This difference probably reflects the different strengths of the two types of pro-apoptotic signals: in wortmannin-treated animals all cell types from the i-cell lineage undergo cell death, whereas upon a two days heat-shock only the interstitial cells and the nematoblasts die when the differentiated cells survive (Table 1). Interestingly after mid-gastric bisection all interstitial cell types located in the head-regenerating tip undergo cell death, mimicking the wortmannin response (Chera et al., 2009). Further analyses should precisely evaluate the distinct sensitivities of the interstitial cell derivatives to the different pro-apoptotic signals and deduce their respective strengths.
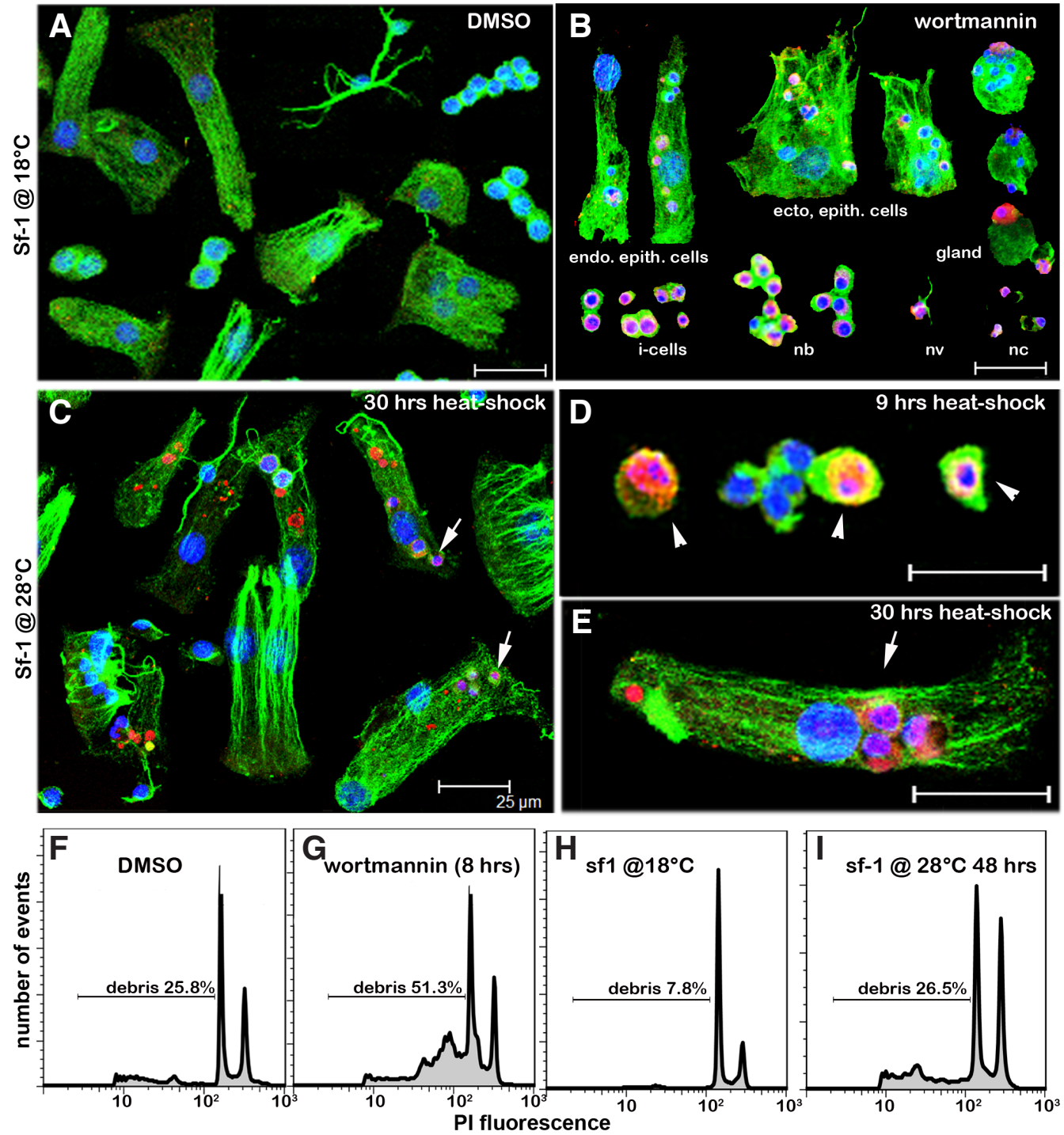

Fig. 5. TUNEL and flow-cytometry detection of DNA fragmentation in sf-1 Hydra exposed to Wortmannin or submitted to heat-shock (HS). (A-E) TUNEL positive nuclei (pink, arrows) identified in the sf-1 Hydra strain after exposure to wortmannin $0.5 \mu \mathrm{M}$ for 8 hours $(\mathbf{A}, \mathbf{B})$ or after a 30 hours $\mathrm{HS}$ at $28^{\circ} \mathrm{C}$ (C-E). Most interstitial cell derivatives are TUNEL positive after wortmannin (B), whereas only few apoptotic interstitial cells (D) could be observed after $9 \mathrm{~h}$ heat-shock. In addition, in case of heat exposure, the nerve cells and nematocytes were still intact after $30 \mathrm{~h}$ (C). In both contexts, epithelial cells contain engulfed apoptotic bodies (arrows) that display intact nuclei (blue, Hoechst). TUNEL staining also detects in the endodermal epithelial cells acidic vacuoles that appear red as weakly stained with DNA dyes. The cytoskeleton was immunodetected with anti alpha-tubulin antibody (green). For abbreviations see Table 1. (F-I) Detection by flow cytometry of the DNA content profile after propidium iodine (PI) labeling. Note the increased amount of nuclear debris in sf-1 Hydra exposed to wortmannin 0.5 $\mu M(\mathbf{F}, \mathbf{G})$ or to a two days heat-shock at $28^{\circ} \mathrm{C}(\mathbf{H}, \mathbf{I})$. These nuclear debris result from DNA fragmentation due to the massive death of cells sensitive to pro-apoptotic signals. 


\section{Perspectives}

Over the past 35 years reports of programmed cell death in Hydra revealed a surprisingly large variety of cell death contexts. These contexts differ not only by the nature of the signals that induce an apoptotic response, these can be metabolic (lack of nutrients), pharmacological, physical (heat), mechanic (wounding, amputation) but also by the responses they generate. As an example two distinct responses were observed in the body column after wounding or bisection, differing by their spreading along the tissues. Indeed after wounding cell death extends over the entire body column, affecting differentiating nematocytes, whereas after mid-gastric bisection apoptosis is asymmetrically restricted to the head-regenerating tip, affecting all precursors and derivatives of the interstitial cell lineage. Elucidating the context-dependent regulation of the apoptotic machinery in Hydra will help us understand the versatility of programmed cell death in animals. The easy experimental access to each of these contexts together with the recent characterization of the molecular apoptotic machinery and the development of a variety of molecular and cellular tools in Hydra render this model system specially attractive for studying the complex regulations and functions of caspases. But Hydra also provide a model to test the parameters that regulate the sensitivity of the cells to pro-apoptotic signals as interstitial cells are obviously the most sensitive when epithelial cells are highly resistant. Understanding the mechanisms that regulate the sensitivity of the different cell types to cell death, is a question with major biomedical implications as resistance to chemotherapy in oncology can result from the survival of cells that are or become resistant to apoptotic signals.

\section{Acknowledgements}

The authors thank Jean-Paul Vincent for providing the Aposensor and Apomut constructs, Patrick Meier for the anti-DIAP antibody, Jean-Claude Martinou for critical reading and helpful comments on this review. Work in our laboratory is supported by the Canton of Geneva, the Swiss National Science Foundation, the National Center of Competence in Research (NCCR) "Frontiers in Genetics", the Human Frontier Science Program (HFSP), the Claraz Donation.

\section{References}

ALEXANDROVA, O., SCHADE, M., BOTTGER, A., DAVID, C.N. (2005). Oogenesis in Hydra: nurse cells transfer cytoplasm directly to the growing oocyte. Dev Biol 281: 91-101.

AUGUSTIN, R., BOSCH, T.C. (2011). Cnidarian immunity: a tale of two barriers. Adv Exp Med Biol 708: 1-16.

BARDET, P.L., KOLAHGAR, G., MYNETT, A., MIGUEL-ALIAGA, I., BRISCOE, J., MEIER, P., VINCENT, J.P. (2008). A fluorescent reporter of caspase activity for live imaging. Proc Natl Acad Sci USA 105: 13901-13905.

BARTKE, T., POHL, C., PYROWOLAKIS, G., JENTSCH, S. (2004). Dual role of BRUCE as an antiapoptotic IAP and a chimeric E2/E3 ubiquitin ligase. Mol Cell 14: 801-811.

BERGMANN, A., STELLER, H. (2010). Apoptosis, stem cells, and tissue regeneration. Sci Signal 3: re8.

BIBB, C., CAMPBELL, R.D. (1973). Cell affinity determining heterospecific graft intolerance in hydra. Tissue Cell 5: 199-208.

BOSCH, T.C. (1986). Immunocompetence in Hydra: epithelial cells recognize selfnonself and react against it. $J$ Exp Zool 238: 225-234.

BOSCH, T.C., DAVID, C.N. (1984). Growth regulation in Hydra: relationship between epithelial cell cycle length and growth rate. Dev Biol 104: 161-171.
BOtTGER, A., ALEXANDROVA, O. (2007). Programmed cell death in Hydra. Semin Cancer Biol 17: 134-146.

BRIEN, P., VAN DEN EECKHOUDT, J.P. (1953). [Budding and regeneration in hydra irradiated with x-rays]. C R Acad Sci, 237: 756-758.

BUZGARIU, W., CHERA, S., GALLIOT, B. (2008). Methods to investigate autophagy during starvation and regeneration in hydra. Methods Enzymol 451: 409-437.

CAMPBELL, R.D. (1976). Elimination by Hydra interstitial and nerve cells by means of colchicine. J Cell Sci 21: 1-13.

CHAPMAN, J.A., KIRKNESS, E.F., SIMAKOV, O., HAMPSON, S.E., MITROS, T., WEINMAIER, T., RATTEI, T., BALASUBRAMANIAN, P.G., BORMAN, J., BUSAM, D., et al. (2010). The dynamic genome of Hydra. Nature 464: 592-596.

CHERA, S., BUZGARIU, W., GHILA, L., GALLIOT, B. (2009a). Autophagy in Hydra: A response to starvation and stress in early animal evolution. Biochim Biophys Acta 1793: 1432-1443

CHERA, S., GHILA, L., DOBRETZ, K., WENGER, Y., BAUER, C., BUZGARIU, W., MARTINOU, J.C., GALLIOT, B. (2009b). Apoptotic cells provide an unexpected source of Wnt3 signaling to drive hydra head regeneration. Dev Cell 17: 279-289.

CHERA, S., GHILA, L., WENGER, Y., GALLIOT, B. (2011). Injury-induced activation of the MAPK/CREB pathway triggers apoptosis-induced compensatory proliferation in hydra head regeneration. Dev Growth Differ 53: 186-201.

CIKALA, M., ALEXANDROVA, O., DAVID, C.N., PROSCHEL, M., STIENING, B., CRAMER, P., BOTTGER, A. (2004). The phosphatidylserine receptor from Hydra is a nuclear protein with potential $\mathrm{Fe}(\mathrm{II})$ dependent oxygenase activity. BMC Cell Biol 5: 26.

CIKALA, M., WILM, B., HOBMAYER, E., BOTTGER, A., DAVID, C.N. (1999). Identification of caspases and apoptosis in the simple metazoan Hydra. Curr Bio/9: 959-962.

DARDING, M., MEIER, P. (2012). IAPs: Guardians of RIPK1. Cell Death Differ 19:58-66.

DAVID, C., SCHMIDT, N., SCHADE, M., PAULY, B., ALEXANDROVA, O., BOTTGER, A. (2005). Hydra and the evolution of apoptosis. Integr Comp Biol 45: 631-638.

DEGTEREV, A., YUAN, J. (2008). Expansion and evolution of cell death programmes. Nat Rev Mol Cell Biol 9: 378-390.

DOMINGUES, C., RYOO, H.D. (2012). DrosophilaBRUCE inhibits apoptosis through non-lysine ubiquitination of the IAP-antagonist REAPER. Cell Death Differ 19: 470-477.

DONTENWILL, M., PASCAL, G., PILETZ, J.E., CHEN, M., BALDWIN, J., RONDE, P. DUPUY, L., UROSEVIC, D., GRENEY, H., TAKEDA, K., BOUSQUET, P. (2003). IRAS, the human homologue of Nischarin, prolongs survival of transfected PC12 cells. Cell Death Differ 10: 933-935.

FEOKTISTOVA, M., GESERICK, P., KELLERT, B., DIMITROVA, D.P., LANGLAIS, C., HUPE, M., CAIN, K., MACFARLANE, M., HACKER, G., LEVERKUS, M. (2011) clAPs block Ripoptosome formation, a RIP1/caspase-8 containing intracellular cell death complex differentially regulated by cFLIP isoforms. Mol Cell 43: 449-463.

FUCHS, Y., STELLER, H. (2011). Programmed cell death in animal development and disease. Cell 147: 742-758.

FUJISAWA, T., DAVID, C.N. (1984). Loss of differentiating nematocytes induced by regeneration and wound healing in Hydra. J Cell Sci 68: 243-255.

FULDA, S., PERVAIZ, S. (2010). Apoptosis signaling in cancer stem cells. Int J Biochem Cell Biol 42: 31-38.

GALLIOT, B., CHERA, S. (2010). The Hydra model: disclosing an apoptosis-driven generator of Wnt-based regeneration. Trends Cell Biol 20: 514-523.

GALLIOT, B., GHILA, L. (2010). Cell plasticity in homeostasis and regeneration. Mol Reprod Dev 77: 837-855.

GAUCHAT, D., ESCRIVA, H., MILJKOVIC-LICINA, M., CHERA, S., LANGLOIS, M.C., BEGUE, A., LAUDET, V., GALLIOT, B. (2004). The orphan COUP-TF nuclear receptors are markers for neurogenesis from cnidarians to vertebrates. Dev Biol 275: 104-123.

HOLSTEIN, T.W., HOBMAYER, E., DAVID, C.N. (1991). Pattern of epithelial cell cycling in hydra. Dev Biol 148: 602-611.

HONEGGER, T.G., ZURRER, D., TARDENT, P. (1989). Oogenesis in Hydra carnea: A new model based on light and electron microscopic analyses of oocyte and nurse cell differentiation. Tissue Cell 21: 381-393.

KALOULIS, K., CHERA, S., HASSEL, M., GAUCHAT, D., GALLIOT, B. (2004). Reactivation of developmental programs: the cAMP-response element-binding protein pathway is involved in hydra head regeneration. Proc Natl Acad Sci USA 101: 2363-2368. 
KANOME, T., ITOH, N., ISHIKAWA, F., MORI, K., KIM-KANEYAMA, J.R., NOSE, K., SHIBANUMA, M. (2007). Characterization of Jumping translocation breakpoint (JTB) gene product isolated as a TGF-beta1-inducible clone involved in regulation of mitochondrial function, cell growth and cell death. Oncogene 26: 5991-6001.

KUZNETSOV, S., LYANGUZOWA, M., BOSCH, T.C. (2001). Role of epithelial cells and programmed cell death in Hydra spermatogenesis. Zoology 104: 25-31.

KUZNETSOV, S.G., ANTON-ERXLEBEN, F., BOSCH, T.C. (2002). Epithelial interactions in Hydra: apoptosis in interspecies grafts is induced by detachment from the extracellular matrix. J Exp Biol 205: 3809-3817.

LANGE, C., HEMMRICH, G., KLOSTERMEIER, U.C., LOPEZ-QUINTERO, J.A., MILLER, D.J., RAHN, T., WEISS, Y., BOSCH, T.C., ROSENSTIEL, P. (2011). Defining the origins of the NOD-like receptor system at the base of animal evolution. Mol Biol Evol 28: 1687-1702.

LASI, M., DAVID, C.N., BOTTGER, A. (2010a). Apoptosis in pre-Bilaterians: Hydra as a model. Apoptosis 15: 269-278.

LASI, M., PAULY, B., SCHMIDT, N., CIKALA, M., STIENING, B., KASBAUER, T., ZENNER, G., POPP, T., WAGNER, A., KNAPP, R.T., HUBER, A.H., GRUNERT, M., SODING, J., DAVID, C.N., BOTTGER, A. (2010b). The molecular cell death machinery in the simple cnidarian Hydra includes an expanded caspase family and pro- and anti-apoptotic Bcl-2 proteins. Cell Res 20: 812-825.

LIN, Y., DEVIN, A., COOK, A., KEANE, M.M., KELLIHER, M., LIPKOWITZ, S., LIU, Z.G. (2000). The death domain kinase RIP is essential for TRAIL (Apo2L)-induced activation of lkappaB kinase and c-Jun N-terminal kinase. Mol Cell Biol 20: 6638-6645.

LINDGENS, D., HOLSTEIN, T.W., TECHNAU, U. (2004). Hyzic, the Hydra homolog of the zic/odd-paired gene, is involved in the early specification of the sensory nematocytes. Development 131: 191-201.

LITTLEFIELD, C.L. (1991). Cell lineages in Hydra: isolation and characterization of an interstitial stem cell restricted to egg production in Hydra oligactis. Dev Biol 143: $378-388$

LUTHRINGER, B., ISBERT, S., MULLER, W.E., ZILBERBERG, C., THAKUR, N.L., WORHEIDE, G., STAUBER, R.H., KELVE, M., WIENS, M. (2011). Poriferan survivin exhibits a conserved regulatory role in the interconnected pathways of cell cycle and apoptosis. Cell Death Differ 18: 201-213.

MARCUM, B.A., FUJISAWA, T., SUGIYAMA, T. (1980). A mutant hydra strain (sf-1) containing temperature-sensitive interstitial cells, in: TARDENT, P., TARDENT, R. (Eds.), Developmental and Cellular Biology of Coelenterates. Elsevier/North Holland, Amsterdam, pp. 429-434.

MARTINEZ, D., BRIDGE, D. (2012). Hydra, the everlasting embryo, confronts aging. Int J Dev Biol 56: 479-487.

MARTINOU, J.C., YOULE, R.J. (2011). Mitochondria in apoptosis: Bcl-2 family members and mitochondrial dynamics. Dev Cell 21: 92-101.

MCDONALD, E.R., 3RD, EL-DEIRY, W.S. (2004). Suppression of caspase-8- and -10-associated RING proteins results in sensitization to death ligands and inhibition of tumor cell growth. Proc Natl Acad Sci USA 101: 6170-6175.

MILJKOVIC-LICINA, M., CHERA, S., GHILA, L., GALLIOT, B. (2007). Head regeneration in wild-type hydra requires de novo neurogenesis. Development 134: 1191-1201.

MILLER, M.A., TECHNAU, U., SMITH, K.M., STEELE, R.E. (2000). Oocyte development in Hydra involves selection from competent precursor cells. Dev Biol 224: 326-338

MIURA, M. (2011). Active participation of cell death in development and organismal homeostasis. Dev Growth Differ 53: 125-136.

MULLER-TAUBENBERGER, A., VOS, M.J., BOTTGER, A., LASI, M., LAI, F.P., FISCHER, M., ROTTNER, K. (2006). Monomeric red fluorescent protein variants used for imaging studies in different species. Eur J Cell Biol 85: 1119-1129.

NISHIMAYA-FUJISAWA, C. (2012). Germline stem cells and sex determination in Hydra. Int J Dev Biol 56: 499-508.

O'CONNOR, W., JR., HARTON, J.A., ZHU, X., LINHOFF, M.W., TING, J.P. (2003). Cutting edge: CIAS1/cryopyrin/PYPAF1/NALP3/CATERPILLER 1.1 is an inducible inflammatory mediator with NF-kappa B suppressive properties. J Immunol 171: 6329-6333.

ORMEROD, M.G. (2000). Flow cytometry: a practical approach, 3rd ed. Oxford University Press, Oxford.
OTTO, J.J., CAMPBELL, R.D. (1977). Tissue economics of hydra: regulation of cell cycle, animal size and development by controlled feeding rates. J Cell Sci 28 : 117-132.

PACHURA, S., CAMBON, J.P., BLAISE, C., VASSEUR, P. (2005). 4-nonylphenolinduced toxicity and apoptosis in Hydra attenuata. Environ Toxicol Chem, 24: 3085-3091.

PODRABSKY, J.E., KRUMSCHNABEL, G. (2010). Cell death beyond worms, flies and humans: Unusual model systems for cell death research. Apoptosis 15: 243-248.

QIU, X.B., MARKANT, S.L., YUAN, J., GOLDBERG, A.L. (2004). Nrdp1-mediated degradation of the gigantic IAP, BRUCE, is a novel pathway for triggering apoptosis. EMBO J 23: 800-810.

RIBEIRO, P.S., KURANAGA, E., TENEV, T., LEULIER, F., MIURA, M., MEIER, P. (2007). DIAP2 functions as a mechanism-based regulator of drICE that contributes to the caspase activity threshold in living cells. J Cell Biol 179: 1467-1480.

SHIMIZU, H. (2012). Transplantation analysis of developmental mechanisms in Hydra. Int J Dev Biol 56: 463-472.

SHIMIZU, S., KONISHI, A., NISHIDA, Y., MIZUTA, T., NISHINA, H., YAMAMOTO, A., TSUJIMOTO, Y. (2010). Involvement of JNK in the regulation of autophagic cell death. Oncogene 29: 2070-2082.

SRINIVASULA, S.M., ASHWELL, J.D. (2008). IAPs: what's in a name? Mol Cell 30: $123-135$

SRIVASTAVA, M., SIMAKOV, O., CHAPMAN, J., FAHEY, B., GAUTHIER, M.E., MITROS, T., RICHARDS, G.S., CONACO, C., DACRE, M., HELLSTEN, U. et al. (2010). The Amphimedon queenslandica genome and the evolution of animal complexity. Nature 466: 720-726.

STRELIN, G.S. (1929). Röntgenologische Untersuchungen an Hydren. II. Die histologischen Verianderungen im Korperbau von Pelmatohydra oligactis unter der Wirkung der Röntgenstrahlen und ihre Bedeutung für die Regeneration und Vermehrung. Roux's Arch Entw Mech Org 115: 26-51.

SUGIYAMA, T., FUJISAWA, T. (1978). Genetic analysis of developmental mechanisms in Hydra. II. Isolation and characterization of an interstitial cell-deficient strain J Cell Sci 29: 35-52.

TECHNAU, U., MILLER, M.A., BRIDGE, D., STEELE, R.E. (2003). Arrested apoptosis of nurse cells during Hydra oogenesis and embryogenesis. Dev Biol260: 191-206.

TENEV, T., BIANCHI, K., DARDING, M., BROEMER, M., LANGLAIS, C., WALLBERG, F., ZACHARIOU, A., LOPEZ, J., MACFARLANE, M., CAIN, K., MEIER, P. (2011). The Ripoptosome, a signaling platform that assembles in response to genotoxic stress and loss of IAPs. Mol Cell 43: 432-448.

TERADA, H., SUGIYAMA, T., SHIGENAKA, Y. (1988). Genetic analysis of developmental mechanisms in hydra. XVIII. Mechanism for elimination of the interstitia cell lineage in the mutant strain Sf-1. Dev Biol 126: 263-269.

VAN VLIERBERGHE, P., MEIJERINK, J.P., LEE, C., FERRANDO, A.A., LOOK, A.T., VAN WERING, E.R., BEVERLOO, H.B., ASTER, J.C., PIETERS, R. (2006). A new recurrent 9q34 duplication in pediatric T-cell acute lymphoblastic leukemia. Leukemia 20: 1245-1253.

VERNOOY, S.Y., CHOW, V., SU, J., VERBRUGGHE, K., YANG, J., COLE, S., OLSON, M.R., HAY, B.A. (2002). Drosophila Bruce can potently suppress Rpr- and Grimdependent but not Hid-dependent cell death. Curr Biol 12: 1164-1168.

WILKINSON, J.C., RICHTER, B.W., WILKINSON, A.S., BURSTEIN, E., RUMBLE, J.M., BALLIU, B., DUCKETT, C.S. (2004). VIAF, a conserved inhibitor of apoptosis (IAP)-interacting factor that modulates caspase activation. $J$ Biol Chem 279: 51091-51099.

YAROSS, M.S., BODE, H.R. (1978). Regulation of interstitial cell differentiation in Hydra attenuata. V. Inability of regenerating head to support nematocyte differentiation. J Cell Sci 34: 39-52.

YI, C.H., YUAN, J. (2009). The Jekyll and Hyde functions of caspases. Dev Cell 16: 21-34.

ZIHLER, J. (1972). Zur Gametogenese und Befructungsbiologie von Hydra. Wilhelm Roux `s Arch. Entwick Mech Org 169: 239-267.

ZOU, H., LI, Y., LIU, X., WANG, X. (1999). An APAF-1.cytochrome c multimeric complex is a functional apoptosome that activates procaspase-9. $J$ Biol Chem 274: 11549-11556. 


\section{Further Related Reading, published previously in the Int. J. Dev. Biol.}

A non-enzymatic microsurgical dissection technique of mouse embryonic tissues for gene expression profiling applications Li Sun, May-Yin Lee and Jacqueline M. Veltmaat

Int. J. Dev. Biol. (doi: 10.1387/ijdb.113424Is)

A polymorphic, thrombospondin domain-containing lectin is an oocyte marker in Hydractinia: implications for germ cell specification and sex determination

Brahim Mali, R. Cathriona Millane, Günter Plickert, Marcus Frohme and Uri Frank Int. J. Dev. Biol. (2011) 55: 103-108

An organizing region in metamorphosing hydrozoan planula larvae - stimulation of axis formation in both larval and in adult tissue

Melanie Stumpf, Britta Will, Karola Wittig, Jennifer Kasper, Benjamin Fischer, Jürgen Schmich, Stefanie Seipp and Thomas Leitz

Int. J. Dev. Biol. (2010) 54: 795-802

Frontiers in fluorescence microscopy

José Rino, José Braga, Ricardo Henriques and Maria Carmo-Fonseca

Int. J. Dev. Biol. (2009) 53: 1569-1579

Glycobiology of fertilization in the pig

Edda Töpfer-Petersen, Mahnaz Ekhlasi-Hundrieser and Miroslava Tsolova

Int. J. Dev. Biol. (2008) 52: 717-736

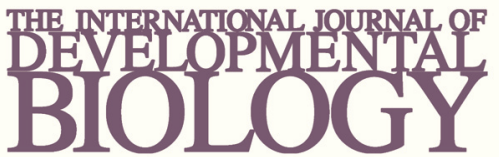

Volume 54 Nos. 6/7

Special Issue
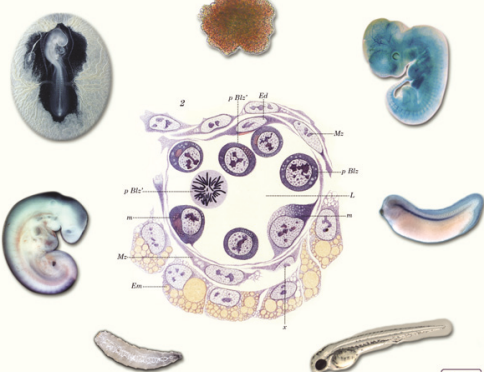

Developmental Hematopoiesis
5 yr ISI Impact Factor $(2010)=2.961$

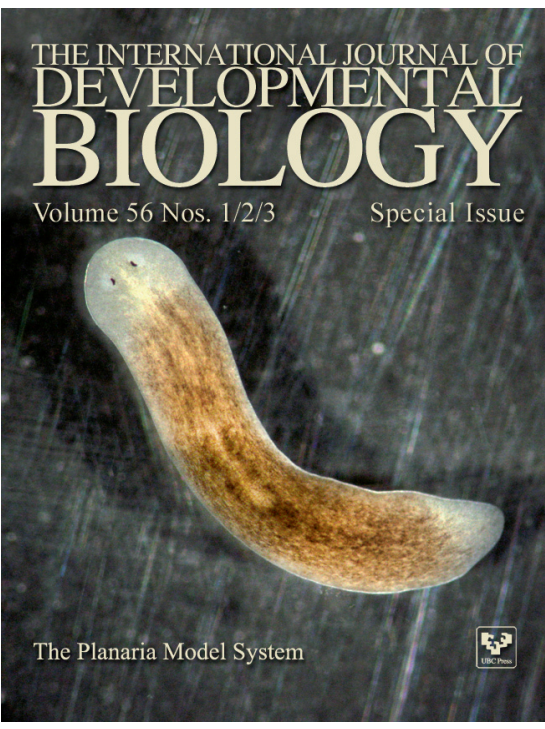

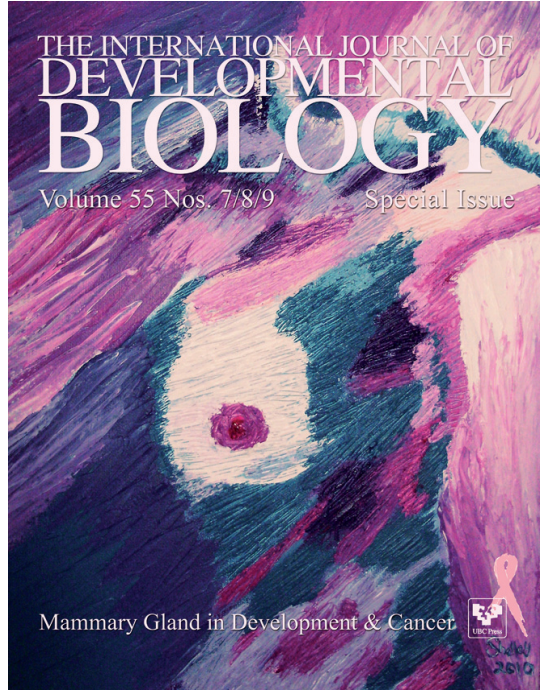

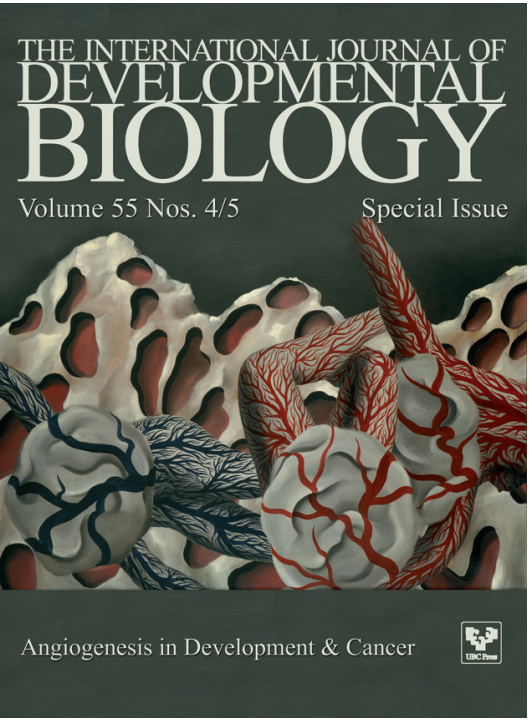

